${ }^{1}$ U.O.C. Ortopedia e Traumatologia Universitaria, A.O.U.S. Santa Maria alle Scotte, Siena, Italy

${ }^{2}$ IInd Università degli Studi di Napoli, Italy

${ }^{3}$ Orthopaedics and Traumatology Clinic Banja Luka, Republic of Srpska, Bosnia and Herzegovina

\title{
FLAT-BACK SYNDROME AS POST TRAUMATIC OR POST SCOLIOSIS TREATMENT DISORDER OF THE SPINE
}

\section{SINDROM RAVNIH LEĐA - POST TRAUMATOLOŠKI I POST SKOLIOZNI POREMEĆAJ KIČME}

\author{
Luigi Meccariello $^{1}$, Sara Cioffi ${ }^{2}$, Predrag Grubor ${ }^{3}$, Raffaele Franzese ${ }^{2}$, Raffaele Cioffi ${ }^{2}$, Salvatore Di Giacinto ${ }^{1}$
}

\section{Summary}

The term flat-back syndrome has been used to describe symptoms resulting from distraction instrumentation into the lower lumbar spine or sacrum and other factors that may aggravate the loss of lumbar lordosis include thoracolumbar kyphosis, fixed thoracic kyphosis, hip flexion contractures, and pseudarthrosis, although loss of lumbar lordosis may occur with modern segmental implant systems if precautions to preserve lumbar lordosis are not taken loss of lumbar lordosis with forward inclination of the trunk, inability to stand upright, and back pain. The aim of this paper is to review the literature to determinate causes and clinical presentation of FlatBack Syndrome.

Key words: Flat-Back Syndrome

\section{Sažetak}

Termin sindrom ravnih leđa se koristi prilikom opisivanja simptoma koji su nastali upotrebom distrakcionih instrumenata $u$ donjem lumbalnom području ili sakrumu kao i drugih faktora koji dovode do gubitka lumbalne lodroze iključujući torakolumbarnu kifozu, fiksiranu torakalnu kifozu, fleksione kontrakture kuka,i pseudoartroza. Gubitak lumbarne lodroze može da nastane korištenjem modernih segmentiranih implantata ako se ne preduzmu mjere koje će spriječiti pojavu lumbarne lordoze. Lumbarna lordoza se javlja i kod prednje inklinacije trupa, gdje dolazi do nemogućnosti stajanja uspravno, pojavljuje se bol u leđima.

Cilj rada je da se pregledom literature utvrde uzorci i kiliničko pojavljivanje sindroma ravnih leđa.

Ključne reči:Sindrom ravnih leđa

\section{Introduction}

The "sagittal disequilibrium" of human spine has been poorly studied in literature due to the lower incidence of the deformities of this anatomic plane respect to those of the axial one. These deformities are represented by the more common scoliosis.

In 1976, Moe and Denis [1] reported on 16 patients with a thoracolumbar fusion presenting the loss of lumbar lordosis and the rise of back pain. They introduced the term flat-back syndrome (FBS). In the past, FBS was considered mainly an iatrogenic complication in the treatment of scoliosis with the Harrington distraction instrumentation [2]. In the last few years other conditions that influence vertebral curves and cause FBS [3] have been identified. The fixed positive sagittal spine imbalance correlated to these states of health changes the patient posture. It has repercussions on the gait causing severe damages not only at the back, but also at the hips and at the knees [4]. The understanding of the FB causes, which are related to surgery, is very important for the planning of a correct rehabilitation program.

The purpose of this paper is to identify all the several different etiologic factors that modify the static and dynamic biomechanical equilibrium of the spine, causing the FB.

\section{Definition and etiology}

Physiological status of the spine has a perfect biomechanical equilibrium on both the sagittal and the frontal plane. In an ideal posture, the body mass center, which is also the centre of gravity, is aligned to the spine axis. The spine axis is represented by a line which passes through the center of C7, located ahead of the dorsal kyphosis, and passes through the center of L3. This is also named the Barrè line. The extension of this ideal line passes through the cranial apex, the acoustic meatus, the shoulder, the great trochanter, the knee, the external perimalleolar region and finishes to the centre of the supporting podalic polygon, which is situated behind the line connecting the femoral heads. The physiological angles of the sagittal curves, the 
pelvic and lombosacral inclination angles maintain this biomechanical balance.

A reduction of the lumbar lordosis angle $\left(<45^{\circ}\right.$ at adulthood and $<20^{\circ}$ at teen-aged, measured with Cobb's method on x-ray in axial projection) causes a biomechanical imbalance of the spine which could sometimes lead to a reduction of the dorsal kyphosis $\left(<25^{\circ}\right.$ at adulthood and $<15^{\circ}$ at teen-age). This dorsal reduction is a biomechanical compensation that could lead to FBS. In same condition the reduction of the reduction of the thoracic kyphosis can be the "primum movens" of FB. By reviewing the literature, we have recognized 9 causes of FB. We have divided these causes in two groups (Table 1).

\section{Table 1: Causes of Flat Back Syndrome}

1.1 Iatrogenic Post-Surgery FB (Kostuik) [4-6,14,15,20-27]

1.2 FB due to Orthesic [16-19]

1.3 Squatting-Posture Degenerative FB [13,29]

1.4 Degenerative Senile FB [30-33]

1.5 Juvenile Astenic FB [34-36]

1.6 FB in female puberty[37-41]

1.7 Spondilitic FB [42]

1.8 FB due to contracted muscular chains

1.9. FB due to Congenital, Metabolic and Genetic Diseases:

- Marfan Syndrome

- Morquio Disease

- Achondroplasia

\subsection{Iatrogenic Post-Surgery FB}

The most frequent condition described by literature is the iatrogenic loss of lordosis as a complication following the placement of thoracolumbar instrumentation, especially with distraction instrumentation spanning the lumbar spine, like the Harrington distraction instrumentation (Figure 1). In 1973, Doherty [5] was the first to describe, in patients treated for scoliosis with the Harrington device on the dorso-lumbar junction, an alteration of the posture. After the studies about the vertebral fusion at dorsolumbar level published by Kostuik and La Grone, nowadays many authors agree that FB appears in patients where the vertebral fusion is distal to L3 [6]. The symptoms included muscular pain in the upper back and lower cervical area, pain in the knees, and inability to stand up right. The distraction action of this surgical instrument has a therapeutic effect on the scoliosis but it lead to reduction of lumbar lordosis.

Another etiologic factor is the pseudoarthrosis caused by the posterior spinal arthrodesis performed as a surgical correction of FB [7]. Herkowitz and coll. have studied the degenerative and pseudoarthrosic complications of surgical treatment of the vertebral sagittal alterations[8]. They have demonstrated that the incidence of post-surgery pseudoarthrosis at lumbar level is $5-7 \%$. The pseudoarthosic complication is more frequent in distal arthrodesis of Spine.
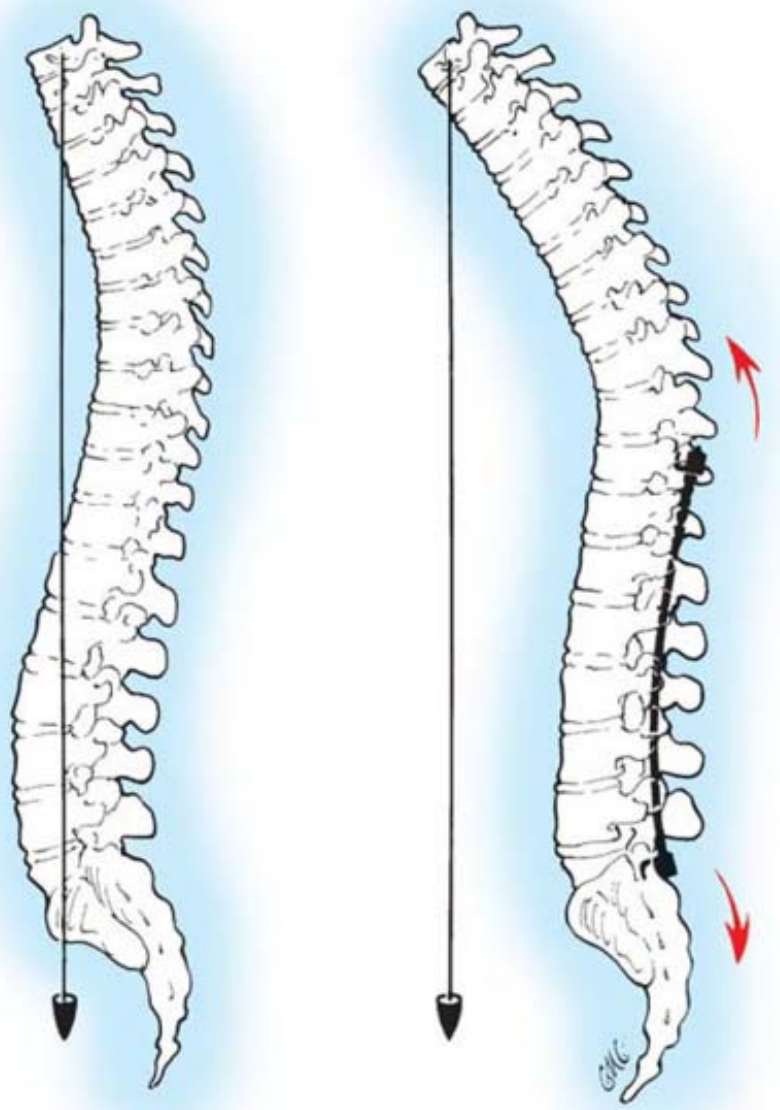

Figure1: Effects of distraction rod in lumbar spine. If contouring for lordosis is inadequate, lumbar spine can be flattened by distracting force. Also note kyphotic deformity just superior to distraction rod. (From Lagrone MO: Loss of lumbar lordosis: a complication of spinal fusion for scoliosis, Orthop Clin North Am 19:383, 1988.)

\subsection{FB due to Orthesic}

Another cause of FB is the use of Milwaukee corset, an orthesis used in the treatment of the dorsal and dorso-lumbar scoliosis in patients aged between 2 and 16. The traction and derotation applied by the corset have a therapeutic effect on the scoliosis but these forces lead to the reduction of the dorsal kyphosis and/or lumbar lordosis, causing FB (Figure 2). For this reason its use has been restricted to particular spinal deformities and other orthesic instruments which don't cause this complication, like the Chènau corset [9], have become more popular. 

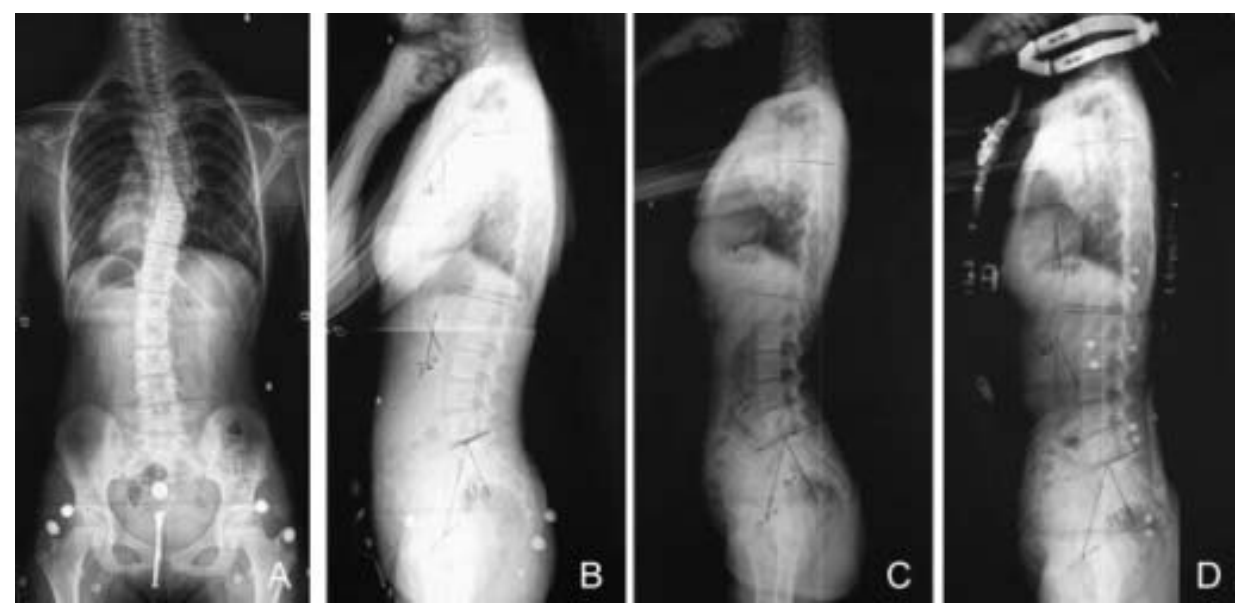

[10]. They showed that patients affected by FB associated to vertebral disks degeneration present a reduction of the sacral angle. A sacral angle inferior than the physiological value $\left(<30^{\circ}\right)$ has a high possibility, over the $80 \%$, to cause a decrease of the lumbar lordosis. Further, these patients are often affected by Schmorl's nodes, common spinal abnormalities regarded as incidental observations on MR images or plain X-rays of the thoracolumbar spine. They may occur in $38 \%$ to $75 \%$

Figure2: The radiographs of the above patient $A$ : The patient had a major thoracic curve of $35^{\circ}$. The Risser sign is 3 degrees. The post-menarche age was 11 months. B: in natural standing posture, TK: $16^{\circ}, L L$ : $32^{\circ}, \mathrm{PI}: 39^{\circ}$. C: with elastic orthotic belt, TK: $4^{\circ}, \mathrm{LL}$ : $32^{\circ}, \mathrm{PI}: 40^{\circ}$. D: with Milwaukee brace, TK: $10^{\circ}, \mathrm{LL}$ : $30^{\circ}$, PI: $39^{\circ}$. The D XR shows the Flat Back Syndrome by Milwaukee brace.

(From Jiang J, Qiu Y, Mao S, Zhao Q, Qian B, Zhu F: The influence of elastic orthotic belt on sagittal profile in adolescent idiopathic thoracic scoliosis: a comparative radiographic study with Milwaukee brace. BMC Musculoskeletal Disorders 2010, 11:219)

\subsection{Squatting-Posture Degenerative FB}

The FB can also have a degenerative etiology. One of the degenerative FB is considered to be a rare disease in Western countries, but in Asian countries it is one of the commonest spinal deformities. It is defined by Takemitsu as "lumbar degenerative kyphosis" [9]. Korean and Japanese screenings [9] show that this vertebral deformity has a greater incidence in female patients aged between 40 and 50 with distinctive life style and jobs. The principal risk factor seems to be working or simply staying in a squatting posture for long periods. This forced position causes a chronic compartment syndrome of lumbar extensor muscles. The pathophysiology of degenerative FB has not been explained yet. However, an extensive degeneration and weakness of lumbar extensor muscles are thought to be responsible for the FB condition in most patients.

\subsection{Degenerative Senile FB}

FB is very common in senile age. The decrease of lumbar lordosis observed particularly in patients after 70 years old, is caused by the degeneration of vertebral disks. Nevertheless, not all the older patients present the FB at the end. Kobayashi et al. studied the postural effects of vertebral disk degeneration at lumbar level on a group of 100 patients, with age superior to 60 years and with a follow up of 10 years of the population [11-12]. These patients often have back pain and other characteristics symptoms of FBS.

\subsection{Juvenile Astenic FB}

Also young people could present a FB. In the asthenic children [13], who have a thoracic kyphosis lower than a normal spine or a kyphosis of the superior lumbar tract or a thoraco-lumbar kyphosis, the spine produces a biomechanical compensation that causes FB. The inferior section of the lumbar spine is in a physiological conformation, with a good sacral orientation, while the middle and superior sections of the dorsal spine tend to lay flat. Between these two zones, exactly between D11-D12 and L3-L2, there is a posterior convexity. Children with these alterations have the thoracic kyphosis and lumbar lordosis abnormally flat when they are sitted. In orthostatic position, instead, the spine increases its curvatures. The primary cause of this condition is the ligaments laxity. Lesur reported that in children under 6 years old, a kyphotic attitude at this level is normal in sitting position. If this attitude continues over this age, it is caused by a ligaments laxity or/and a scarce trophism of the paravertebral muscels. During the growth age the spine has different conformations: just over the age of 6 it is nearly flat; between 8 and 10 the lumbar lordosis increases; at the age of 12-13 the dorsal spine tends to decrease the kyphosis. Spine has a definitive conformation at puberal age, when the characteristic curvature of the spine and plantar arcs are completed [14].

\section{6. $F B$ in female puberty}

Another form of FB can be identified in puberty, with great incidence in female patients. In this period of life, between the age of 7 and 15, the spine has some physiological modifications consisting in a decrease of the thoracic kyphosis, with a peak at the age 12. This is for female sex the period of maximum puberal development that predisposes some young patients to FB. At this age FB is often associated to scoliosis because the spine has a reduced capacity to support 
axial load [15-16]. The FB alteration further affects this capacity worsening the scoliosis. In this case the reduced thoracic kyphosis is the "primum movens" of the pathology while the reduction of the lumbar lordosis angle represent a biomechanical compensation of spine.

\subsection{Spondilitic $F B$}

A well recognized FB is the one caused by ankylosing spondylitis, a pathology that affects the axial skeleton and consists of a progressive and diffused articular stiffness. The stiffness is the result of a chronic inflammatory process of the connective tissue that involves the tendon insertions (enthesitis) of the ligaments and articular capsules in which the characteristic process of ossifications (sindesmophytes) take place. These patients show a marked stiffness, pain at the hips and at the lumbo-sacral tract, with a progressive reduction of the lumbar lordosis, that evolves to a FB. The progression of the inflammatory process is upward, with a diffused stiffness in the final stage of the pathology. It involves hips, shoulders and all the spine. It can produce a limitation of the thoracic motility that affects the respiratory processes [17].

\subsection{FB due to contracted muscular chains}

The postural alterations on the axial plane of the spine in patients affected by FB is partially compensated by physiological mechanisms, such as: iperextension of hips, anteverting of pelvis and the flexion of knees. If these physiological mechanisms are compromised FB becomes uncovered. The causes can be: a contrattural state of the flexor muscles or an atrophic state of the extensor muscles. (Table 2).

Table 2: Muscles involved in the maintenance of posture

\section{Anteverting muscles}

Retroverting muscles

- Lumbars (Sacral-spinal,

- Trasverse

Ileo-costal of loins,

Multibifidus of spine,

Lumbar

Trasversospinalis)

- Rectus femoris

- Tensor fasciae - latae

- Sartorius

- Ileo-psoas

- Adductor medium and minimus

\section{Genetic Diseases \\ - Marfan Syndrome \\ - Morquio Disease \\ - Achondroplasia}

1.9. FB due to Congenital, Metabolic and

\section{Clinical presentation}

The clinical presentation of FBS is strictly correlated to the loss lumbar lordosis and/or loss thoracic kyphosis. The patients affected by FBS refer: pain and stiffness of the spine, pain of the anterior portion of the thigh, hips and knees pain. Often they also have difficulty in standing up and walk in flexed posture. Flexion contractures of the hips are frequent on examination, and the pelvic tilt may be abnormal $[9,13,17]$. Some female refer to feel pain during the sexual activity. The dyspareunia is caused by the alteration of the physiological anteversion of the uterine angle, wich can be present in patients affected by FB. Physical examination reliably demonstrates the obligatory flattening of the lumbar region and forward tilting of the trunk. By trying to compensate this fixed sagittal imbalance, the patient flexes the knees and hyperextend the cervical spine and any remaining mobile vertebral segments in the thoracic and lumbar spine. Furthermore, his/her attempts to compensate the imbalance and maintain a horizontal gaze may cause in increased strain, pain, and degenerative changes within the cervical spine. Degenerative cervical changes have been documented in $>50 \%$ of the patients with longterm follow-up after a surgical fusion for adolescent idiopathic scoliosis [18]. Sarwahi et al. [19] performed gait analysis on twentyone patients with FBS and found decreased step and stride length as well as gait velocity. Cadence was maintained compared with that of normal controls, whereas the stance phase and hip and knee flexion were increased. In addition, these patients have a particular malocclusion, the mandibular prognathism [19]. All this confirms the physiopathologic link between posture alteration an stomatognathic apparat. Over time this unnatural posture induces muscle fatigue and pain outlining the FBS.

During the clinical examination the patient's back has to be inspected nude, in indifferent orthostatic position. In the static analysis we have to consider: the position of foots, the alignment of inferior limbs, the pelvis position, the symmetry of the hips, abdomen and spine. In the dynamic evaluation we have to consider: the deambulation, any possible equilibrium alteration, osteo-tendineous reflexes, abdomen and paravertebral muscles trophism, knees flexion-extension, antevertion and retrovertion of the pelvis in iperextension and in prone position, pain on the spinous apophysis. The most sensible clinical test is the evaluation of the sagittal arrows in relation to orthostatic position. This test allows to calculate sagittal deviations (Figure 3). 


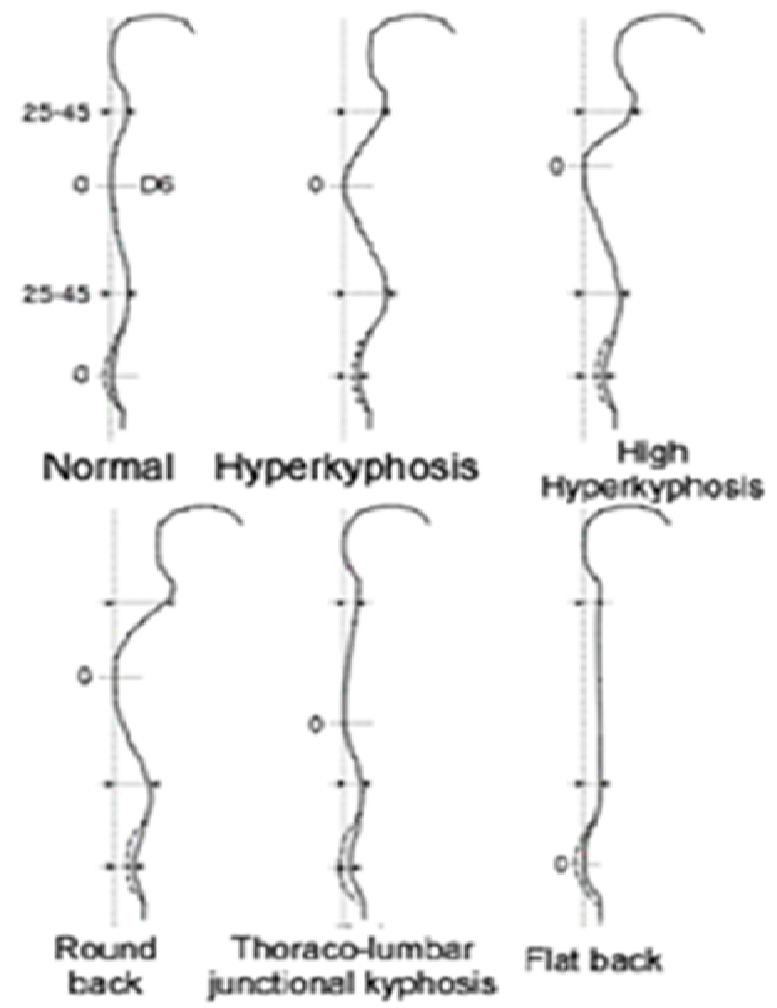

Figure 3: The evaluation of the sagittal arrows in relation to orthostatic position in different Type of Spine deformity.

The patient has to stay in an orthostatic position, with the head, back and buttock leaned on a posterior rigid plane; in this position it is possible to estimate the distance between spine curves and the plane. In the patient affected by FB some typical alterations can be observed. The distance can be decreased at cervical level and/or, very decreased at dorsal and lumbar level $(<20 \mathrm{~mm})$. It is possible to have an equivalent evaluation by utilizing the plumb-line. At the inspection a patient affected by FB can have all or some of these signs:

- head in an hyperextension attitude

- flat or kyphotic cervical spine

- thoracic anterior-posterior diameter decreased, "sole chest" (sometimes alteration of respiratory function for decrease of pulmonary capacity)

- anterior inclination of trunk

- $\quad$ wide shoulders and shoulder blade wings

- lumbar andlor dorsal spine flat

- $\quad$ spine profile flat (rarely)

- hips in hyperextension and pelvis anteverted

- $\quad$ knees in flexion

- slight club-foots

- equilibrium alterations (valuation with Barany test, Romberg test, Babinski-Weil
Discussions

We have analyzed the FB pathology in its complexity. We reviewed the literature by detecting every cause as possible. We have explained the biomechanical and fisiopatological alterations correlated to every recognized causes.

FB is not much dealt in literature because it is often asymptomatic. The difficulty to early identify the FB is that often the patients affected by this pathology do not present a clear symptomatology. They present the typical FBS symptoms only when the pathology is in an advanced state. Exceptions are the iatrogenic FBs because these kind of condition is always correlated to high level of pain. This is the reason why most of the literature we have analyzed focused on this cause.

The young and the astenic FBs are often asymptomatic. Patients don't have pain and there aren't evident postural alterations. In this cases a primary prevention and a more accurate clinical control are necessary. Perhaps elderly patients with the characteristic clinical presentation of FB were already affected by this pathology at teen age but they were asymptomatic. An early diagnosis allows to start a rehabilitation program as soon as possible preventing the evolution of the pathology and the development of its painful symptomatology and dangerous pathologic posture.

The early diagnosis could be possible by the identification of patients with risk factors. Very probably the incidence of $\mathrm{FB}$ in the population is higher than normal should be inserted in a screening program of prevention. These categories include: all the subjects treated with Harrington distraction instrumentation; subjects aged between 7-15 years, in particular female subjects; professional categories that support particular axial stress on the spine (builders, workers that use pneumatic drill, escavatings) or assume particular work position (cobblers); athletes who experience axial stress on the spine (drivers, bodybuilders); subjects with a sacral inclination angle $10^{\circ}$ minor than the physiological value.

FB can be considered the expression of a pathologic morphotype of the spine, an important spine pathology, that can cause an important spine degeneration and marked posture alteration, which ought to have more attention in the future.

\section{Conflict of interest statement}

All authors disclose any financial and personal relationships with other people or organisations that could inappropriately have influenced (bias) this work. 


\section{References}

1. Moe J. H., Denis F.: The iatrogenic loss of lumbar lordosis. 1977

2. J. L. Cummine, J. E. Lonstein, J. H. Moe, R. B. Winter, D. S. Bradford: Reconstructive surgery in the adult for failed scoliosis fusion. 1979

3. JC de Mauroy, J Sengler, P Fender, JJ Lalain, B Tato, P Lucenti, M Goss, G Ferracane: Deviazioni antero posteriori del rachide.Enciclopedie MedicoChirurgicale.2001

4. Choon-Sung Lee, Choon-Ki Lee, Yung-Tae Kim, Young-Mi Hong, Jeong-Hyun Yoo, Dynamic sagittal imbalance of the spine in degenerative flat back. SPINE.2001, Lippincott Williams \& Wilkins, Inc..

5. Doherty J. H.: Complications of fusion in lumbar scoliosis. 1973

6. J. P. Kostuik , G. R. Maurais , W. J. Richardson , et al: Combined single stage anterior and posterior osteotomy for correction of iatrogenic lumbar kyphosis. Spine. 1988

7. De Giorgi G, Gentile A.et al.: "Analyse par ordinateur des possibilités de correction par le corset de Milwauke et de Boston ". Réunion du GES, 1986

8. Herkowitz, Harry N.; Dvorak, Jiri; Bell, Gordon R.; Nordin, Margareta; Grob, Dieter: Lumbar Spine, The Official Publication of the International Society for the Study of the Lumbar Spine, 3rd Edition. Principles of Spinal Instrumentation in Degenerative Disorders of the Lumbar Spine. 2004 Lippincott Williams \& Wilkins

9. Takemitsu Y, Harada Y, Iwahara T, et al. Lumbar degenerative kyphosis: clinical, radiological and epidemiological studies. Spine 1988
10. T. Kobayashi, Y. Atusa, T. Matsuno, et al. A longitudinal study of congruent sagittal spinal alignment in an adult cohort. Spine, 2004

11. Andrew L. Wagner, F. Reed Murtagh, John A. Arrington, and Dexter Stallworth: Relationship of Schmorl's Nodes to Vertebral Body Endplate Fractures and Acute Endplate Disk Extrusions. AJNR Am J Neuroradiol 21:276-281, February 2000

12. Hilton RC, Ball J, Benn RT. Vertebral end plate lesions (Schmorl's nods) in the dorsolumbar spine. Ann Rheum Dis 1976;35:127-132

13. Resnick D, Niwayama G. Intravertebral disc herniations: cartilaginous (Schmorl's) nodes. Radiology 1978;126:57-6

14. S. Pivetta, M. Pivetta: Tecnica della ginnastica medica - Cinesiterapia dei vizi posturali e dei dimorfismi. 2002

15. Lesur J.: Manuel de gymnastique mèdicale. Decima edizione (prima edizione 1956)

16. Kapandji: Fisiologia articolare, 2006

17. C. Formica: Sviluppo fisiologico del profilo sagittale del rachide e insorgenza della Scoliosi. Spine Group-Genova. 2007

18. Kajsa Kelly Duke: The Design of Instrumentation for Force Measurement During Scoliosis Surgery. Spring 2001.

19. Sarwahi V, Boachie-Adjei O, Backus SI, Taira G. Characterization of gait function in patients with postsurgical sagittal (flatback) deformity: a prospective study of 21 patients. Spine. 2002;27:2328-37 